\title{
Hypolipidaemic, gastrointestinal and related responses of broiler chickens to chitosans of different viscosity
}

\author{
BY A. RAZDAN AND D. PETTERSSON \\ Department of Food Science, Swedish University of Agricultural Sciences, S-750 07 Uppsala, \\ Sweden
}

(Received 20 February 1995 - Revised 27 December 1995 - Accepted 6 February 1996)

\begin{abstract}
Broiler chickens (1-d-old) were fed ad libitum on a control diet based on maize and maize starch or diets containing low-, medium- or high-viscosity chitosans at an inclusion level of $15 \mathrm{~g} / \mathrm{kg}$. Body weights and feed intakes of chickens given chitosan-containing diets were generally depressed in comparison with those of control-fed animals on days 11 and 18 of the experiment. On days 12 and 19, feeding the lowviscosity-chitosan diet reduced plasma triacylglycerol and total plasma cholesterol concentrations in relation to chickens receiving the control diet, while the medium- and high-viscosity-chitosan-containing diets reduced total plasma cholesterol and elevated, although not significantly, plasma HDL-cholesterol concentrations compared with those of control-fed animals. Chitosan feeding generally improved plasma HDL-cholesterol: total cholesterol ratio in comparison with control feeding, which was attributed to the general reductions in plasma cholesterol concentrations rather than increases in plasma HDL-cholesterol concentrations. Feeding the high-viscosity-chitosan-containing diet significantly reduced the ileal digestibility of crude protein $(\mathbf{N} \times 6.25)$ and crude fat compared with chickens given the control diet. The reduction in ileal crude fat digestibility was greatest among chickens receiving the high-viscositychitosan-containing diet and chitosan-containing diets reduced ileal fat digestibility by $8 \%$ on average compared with that of control-fed birds. However, increasing the viscosity of the chitosan fraction could not be correlated with increases in terminal ileal digesta viscosity and, therefore, it could not be established that increased ileal lumen viscosity alone contributed to reductions in body weight, feed intake and plasma cholesterol concentrations. However, the fact that ileal digestibility of fat was reduced by feeding chitosan to chickens suggests the action of other hypolipidaemic mechanisms.
\end{abstract}

Chitosan: Plasma lipids: Digestibility: Viscosity : Chickens

Chitosan can be defined both chemically and physiologically as a dietary fibre since it is an NSP which cannot be degraded by the digestive enzymes of man. The growing interest in the nutritional and physiological effects of chitosan has been exemplified by the publication of the first report on the hypocholesterolaemic response of human subjects to these polyglucosamines (Maezaki et al. 1993), while research efforts before this report were focused entirely on animal studies.

Since polyglucosamines are the second-most-ubiquitous dietary-fibre polysaccharides after cellulose, with an estimated $1.2 \times 10^{5}$ tonnes annually accessible on a worldwide basis (Knorr, 1991), it is reasonable to assume that much more research regarding the nutritional significance of these important dietary fibres is to be expected. Chitosan is derived from chitin, a structural polymer of the arthropods and certain fungi, and is extracted by alkaline fusion whereby the chitin is deproteinized, demineralized and de-acetylated (Knorr, 1991). The process can be adapted to yield chitosans with a wide range of degree of acetylation, molecular weight and viscosity. These characteristics of the dietary fibre are assumed to be associated with the reductions in hepatic cholesterol, plasma triacylglycerols and plasma cholesterol as well as increases in HDL-cholesterol and faecal excretion of neutral steroids 
observed in animal experiments (Furda, 1983; Ikeda et al. 1993; Razdan \& Pettersson, 1994). Chitosan, which is largely deacetylated, possesses cationic $\mathrm{NH}_{4}^{+}$groups located on the polyglucosamine chain (Sugano et al. 1980). Chitosan as a result may have a bile acidbinding capacity, causing entrapment or disintegration of mixed micelles in the duodenum and ileum (Furda, 1983). This interruption in enterohepatic bile acid circulation would lead to reduced lipid absorption and increased faecal sterol excretion. Chitosan is relatively insoluble in water but is soluble in dilute acids, giving rise to highly-viscous solutions (Sugano et al. 1988). It has been suggested that viscous dietary fibres such as chitosan inhibit uptake of dietary lipids by increasing the thickness of the intestinal lumen boundary layer (Johnson \& Gee, 1981; Furda, 1990), a proposal supported by evidence obtained from numerous animal experiments (Sugano et al. 1980, 1988; Ikeda et al. 1993).

The present experiment was performed in order to determine the influence of ad libitum feeding of a control diet or control diet supplemented with three chitosans of low, medium and high viscosities on production results, plasma lipid concentrations, ileal digestibilities and caecal short-chain fatty acid (SCFA) concentrations in broiler chickens. An additional aim of the experiment was to establish the general effects of feeding chitosan-containing diets at a low chitosan inclusion level to broilers.

\section{MATERIALS AND METHODS}

\section{Chitosan fractions}

Deacetylated chitin fractions of low, intermediate or high viscosity $(9,510$ and $2200 \mathrm{mPa} . \mathrm{s}$ respectively) were supplied by Pronova Biopolymer, Drammen, Norway. The chitosan fractions were 85,89 and $82 \%$ deacetylated respectively from chitin, according to Pronova Biopolymer standard methods.

\section{Diets}

The chickens received a control diet (Table 1) based on maize $(598.5 \mathrm{~g} / \mathrm{kg}$ feed) and maize starch $(178.5 \mathrm{~g} / \mathrm{kg}$ feed) or isoenergetic diets in which part $(30 \mathrm{~g} / \mathrm{kg})$ of the maize starch component was substituted with 9,510 or $2200 \mathrm{mPa}$.s deacetylated chitin (CH9, CH510 and $\mathrm{CH} 2000$ chitosans respectively). Chitosans were included in the chitosan-containing diets at a level of $15 \mathrm{~g} / \mathrm{kg}$ (Table 1). The inclusion of a high animal-fat content in the chitosan-containing diets was planned to maintain equal metabolizable energy content between diets. Lysine and methionine were included at a level of 4.0 and $1.9 \mathrm{~g} / \mathrm{kg}$ in each of the mash diets, milled to pass a $3.5 \mathrm{~mm}$ screen.

\section{Chickens}

A total of 224 1-d-old broiler chickens (Ross) of mixed sex were divided into sixteen groups of fourteen chickens with an average group weight of $597 \mathrm{~g}$ and a maximum difference in weight of $4 \mathrm{~g}$ between groups. The groups were randomly allocated to four-tier battery cages with raised wire floors in a windowless, light- and temperature-controlled room. The four experimental diets were randomly assigned to four replicates (cages) each. Chickens were wing banded and their sex determined on day 1 of the experiment. All diets were given ad libitum and the birds had free access to feed except for $8 \mathrm{~h}$ before blood collection for analysis of plasma lipids on days 12 and 19. Chickens had free access to water for the duration of the experiment.

\section{Production study}

Individual chicken weights and group cumulative feed intake were recorded at 11 and $18 \mathrm{~d}$ of age and group feed conversion ratios were calculated on a weight-gain basis. 
Table 1. Composition of the control or chitosan-containing broiler chicken diets $(\mathrm{g} / \mathrm{kg}$ airdry basis)

\begin{tabular}{|c|c|c|}
\hline Diet... & Control & Chitosan-containing \\
\hline Maize & 598.5 & $598 \cdot 5$ \\
\hline Fish meal & $101 \cdot 5$ & 101.5 \\
\hline Meat-and-bone meal & $90 \cdot 4$ & 90.4 \\
\hline Animal fat & $9 \cdot 9$ & 24.9 \\
\hline Maize starch & 178.5 & $148 \cdot 5$ \\
\hline Chitosan & - & $15 \cdot 0$ \\
\hline Monocalcium phosphate & $2 \cdot 1$ & $2 \cdot 1$ \\
\hline Vitamin and trace element premix* & $10 \cdot 0$ & $10 \cdot 0$ \\
\hline $\mathrm{NaHCO}_{3}$ & $1 \cdot 0$ & 1.0 \\
\hline Cholesterol & $2 \cdot 0$ & $2 \cdot 0$ \\
\hline Lysine hydrochloride & 4.0 & 4.0 \\
\hline DL-Methionine & 1.9 & 1.9 \\
\hline
\end{tabular}

* For details, see Pettersson \& Åman (1992).

\section{Plasma lipid study}

At both days 11 and 19 , chickens were starved for $8 \mathrm{~h}$ after which two birds from each cage (one of each sex), with weights as close as possible to the average group weight, were slaughtered by cervical dislocation. Blood samples were collected from the jugular veins of each chicken for triacylglycerol and cholesterol analysis.

\section{Digestibility study}

On day 22, one randomly selected bird from each of the four cages per diet from cages containing chickens given control, $\mathrm{CH} 9, \mathrm{CH} 510$ or $\mathrm{CH} 2000$ chitosan-containing diets were slaughtered by cervical dislocation. Thereafter, culling occurred every fourth hour for a further $20 \mathrm{~h}$. At slaughter the gastrointestinal tracts of the chickens were quickly removed and the contents of the small intestine were collected, pooled for each group (cage), frozen $\left(-25^{\circ}\right)$ and freeze-dried. Digestibilities in the digesta samples were calculated relative to the $\mathrm{Cr}_{2} \mathrm{O}_{3}$ marker.

\section{Chemical analysis}

All analyses were carried out in duplicate and results expressed on a DM basis. Before analysis, representative feed samples were ground in a Tecator Cyclone Mill (Tecator AB, Höganäs, Sweden) to pass a $0.5 \mathrm{~mm}$ screen. Viscosities of the chitosan fractions were determined at $25^{\circ}, \mathrm{pH} 4 \cdot 5$, by Pronova Biopolymers according to their standard methods. Samples of freeze-dried digesta were ground in a Retsch mill (Retsch Gmbh, Dusseldorf, Germany; $0.5 \mathrm{~mm}$ screen size). Viscometric analysis of freeze-dried digesta samples was performed. Representative ileal digesta samples were mixed with $0.05 \mathrm{M}$-Trizma- $\mathrm{HCl}$-base buffer ( $\mathrm{pH} \mathrm{7.5)}$ in the proportions, one part freeze-dried digesta and three parts buffer, boiled for $1 \mathrm{~h}$ and centrifuged at $12000 \mathrm{~g}$, after which the supernatant fraction was decanted. Viscometric analysis of sample supernatant fractions was performed using a Bohlin VOR Rheometer system (Bohlin Reologi, Science Park Ideon, Lund, Sweden) at a shear rate of $2 \cdot 31 / \mathrm{s}$; measuring temperature was $40^{\circ}$ and a cone plate geometry system (C25) with a torque element of $1 \mathrm{~N}$.m was used.

Fresh duodenal and ileal digesta samples were collected and frozen at $-20^{\circ}$ for $\mathrm{pH}$ analysis. DM was determined by oven-drying at $105^{\circ}$ for $16 \mathrm{~h}$. Ash and crude protein $(\mathrm{N} \times 6.25)$ were analysed according to standard methods of the Association of Official 
Analytical Chemists (1984). Crude fat was extracted with diethyl ether in a Tecator Soxtec System HT after $3 \mathrm{M}-\mathrm{HCl}$ acid-hydrolysis (Anon, 1971). Starch was determined enzymically (Åman \& Hesselman, 1984). Total dietary fibre, defined as the sum of NSP and Klason lignin, was determined according to Theander \& Westerlund (1986). However, polyglucosamines derived from chitosan are not derivatized to a component detected by the GLC procedures used and, therefore, were not analysed. $\mathrm{Cr}_{2} \mathrm{O}_{3}$ was determined according to Fenton \& Fenton (1979).

Caecal samples were extracted in $50 \mathrm{~mm}-\mathrm{Trizma}-\mathrm{HCl}$ buffer $(\mathrm{pH} 6.5)$ to a sample concentration of $1 \mathrm{mg} / \mathrm{ml}$ and analysis of caecal SCFA was performed by GLC. A chromotograph equipped with a flame-ionization detector (model 5880A; Hewlett Packard, Avondale, PA, USA) was used. The glass column $(2 \mathrm{~m} \times 3 \mathrm{~mm}$ i.d. $)$ was packed with a Carbo Pack Supelco stationary phase. Injection volume was $10 \mu \mathrm{l}$ and injector and oven temperatures were maintained at $200^{\circ}$. The carrier gas was $\mathrm{N}_{2}$ at a flow-rate of $15 \mathrm{ml} / \mathrm{min}$.

Plasma was isolated from blood samples by centrifugation $(200 \mathrm{~g})$ and triacylglycerol, total cholesterol and HDL concentrations were analysed using enzymic colorimetric kits (Boehringer Mannheim Diagnostica, Mannheim, Germany).

\section{Calculations and statistical analysis}

Statistical analysis of the variables (production results, plasma cholesterol, HDLcholesterol and triacylglycerol concentrations as well as ileal digestibility values) was performed by ANOVA, the general linear model (GLM) supported by the statistical analysis system (Statistical Analysis Systems Institute Inc., 1985). In the statistical model the main effects of diet (control or chitosan-containing) and bird age were considered. The effect of sex was not considered when analysing production and digestibility variables, since these results are presented as cage means and, therefore, estimates of dietary effects were performed over sex. The pooled standard errors stated in the tables were obtained from the statistical analysis of cage means.

\section{RESULTS}

Diets

The starch content of the control diet was 614.6 and $593.4 \mathrm{~g} / \mathrm{kg}$ on average for the chitosancontaining diets, measured on a DM basis (Table 2). Crude protein accounted for $183.8 \mathrm{~g} / \mathrm{kg}$ DM content of the control diet and $196.4,192.6$ and $190.5 \mathrm{~g} / \mathrm{kg} \mathrm{DM}$ of the CH9, CH510 and $\mathrm{CH} 2000$ chitosan-containing diets respectively. Crude fat content was approximately $66 \mathrm{~g} / \mathrm{kg} \mathrm{DM}$ content of the control diet and $82.6 \mathrm{~g} / \mathrm{kg}$ on average for the chitosan-containing diets. The ash content of both control and chitosan-containing diets was similar and accounted for $78.2 \mathrm{~g} / \mathrm{kg}$ and approximately $78.7 \mathrm{~g} / \mathrm{kg}$ of the control and chitosan-containing diets respectively. Total dietary-fibre polysaccharide content for the control diet was $46.4 \mathrm{~g} / \mathrm{kg} \mathrm{DM}$ content and the chitosan diets contained $46.7,44.4$ and $43.4 \mathrm{~g} / \mathrm{kg}$ DM content of $\mathrm{CH} 9, \mathrm{CH} 510$ and $\mathrm{CH} 2000$ respectively. The dominating residues for all diets were arabinose, xylose, glucose and uronic acids.

\section{Production study}

Mortality for the entire experiment was $2 \%$ and was not significantly affected by diet or bird age. For the duration of the experiment, broiler chicken live weights, feed intakes and feed conversion ratios were not significantly influenced by diet. Feeding chitosancontaining diets generally reduced body weight and cumulative feed intake in comparison with control-fed chickens (Table 3 ). The exception to this was body weights of chickens given the $\mathrm{CH} 510$ diet on day 18 which were higher than those for animals given other diets. 
Table 2. Chemical composition ( $\mathrm{g} / \mathrm{kg}$ dry matter) of the control and chitosan-containing broiler chicken diets*

\begin{tabular}{|c|c|c|c|c|}
\hline \multirow[b]{2}{*}{ Diet... } & \multirow[b]{2}{*}{ Control } & \multicolumn{3}{|c|}{ Chitosan-containing } \\
\hline & & $\mathrm{CH} 9$ & CH510 & $\mathrm{CH} 2000$ \\
\hline Starch & $614 \cdot 6$ & $592 \cdot 4$ & $594 \cdot 5$ & $593 \cdot 2$ \\
\hline Crude protein & $183 \cdot 8$ & $196 \cdot 4$ & $192 \cdot 6$ & $190 \cdot 5$ \\
\hline Crude fat (HCl) & $65 \cdot 7$ & $82 \cdot 3$ & $84 \cdot 0$ & $81 \cdot 5$ \\
\hline Ash & $78 \cdot 2$ & $78 \cdot 7$ & 78.9 & $78 \cdot 5$ \\
\hline \multicolumn{5}{|l|}{ Dietary-fibre polysaccharides } \\
\hline Arabinose & $8 \cdot 1$ & $8 \cdot 0$ & $8 \cdot 2$ & $8 \cdot 2$ \\
\hline Xylose & $11 \cdot 3$ & $11 \cdot 3$ & $11 \cdot 6$ & $11 \cdot 7$ \\
\hline Glucose & $15 \cdot 2$ & $12 \cdot 2$ & $16 \cdot 5$ & 13.8 \\
\hline Uronic acids & $5 \cdot 0$ & $3 \cdot 2$ & 3.5 & 3.8 \\
\hline Total dietary-fibre polysaccharides & $46 \cdot 4$ & $46 \cdot 7$ & $44 \cdot 4$ & $43 \cdot 4$ \\
\hline
\end{tabular}

$\mathrm{CH} 9, \mathrm{CH} 510, \mathrm{CH} 2000$, low-, intermediate- and high-viscosity (9, 510 and $2000 \mathrm{mPa} . \mathrm{s}$ respectively) deacetylated chitin fractions (Pronova Biopolymers, Drammen, Norway).

* For details of composition, see Table 1.

Table 3. Live weight, cumulative feed intake and feed conversion ratio of broiler chickens given control or chitosan-containing diets*

\begin{tabular}{|c|c|c|c|c|c|c|}
\hline & \multirow[b]{2}{*}{ Control diet } & \multicolumn{3}{|c|}{ Chitosan-containing diets } & \multirow[b]{2}{*}{ Pooled SEM $\dagger$} & \multirow{2}{*}{$\begin{array}{c}\text { Statistical } \\
\text { significance of } \\
\text { differencet: } P=\end{array}$} \\
\hline & & CH9 & $\mathrm{CH} 510$ & $\mathrm{CH} 2000$ & & \\
\hline \multicolumn{7}{|c|}{ Body wt (g) } \\
\hline Day 11 & 202 & 187 & 192 & 188 & $6 \cdot 0$ & 0.09 \\
\hline Day 18 & 419 & 404 & 424 & 401 & $15 \cdot 3$ & 0.23 \\
\hline \multicolumn{7}{|c|}{ Cumulative feed intake (g) } \\
\hline Day 11 & 234 & 213 & 222 & 219 & $7 \cdot 4$ & 0.09 \\
\hline Day 18 & 579 & 562 & 565 & 559 & 17.8 & 0.13 \\
\hline \multicolumn{7}{|c|}{ Feed conversion ratio ( $\mathrm{g}$ feed/g weight gain) } \\
\hline Day 11 & 1.47 & 1.48 & 1.48 & $1 \cdot 50$ & $0 \cdot 01$ & $0 \cdot 18$ \\
\hline Day 18 & 1.55 & 1.55 & 1.48 & 1.56 & $0 \cdot 04$ & $0 \cdot 90$ \\
\hline
\end{tabular}

* For details of diets and procedures, see Tables 1 and 2 and p. 388.

+ df 12.

$\$$ Control $v$. chitosan-containing diets; all differences were not significant.

\section{Plasma lipid study}

Plasma triacylglycerol, total plasma cholesterol, plasma HDL-cholesterol and plasma HDL-cholesterol:total cholesterol ratio were generally not significantly affected by diet or age of the animals. In general, feeding the $\mathrm{CH} 9$ chitosan diet reduced plasma triacylglycerol, total plasma cholesterol, plasma HDL-cholesterol and increased plasma HDL-cholesterol: total cholesterol ratio in relation to control-fed animals on days 12 and 19 (Table 4). Feeding chitosan-containing diets generally decreased plasma cholesterol concentrations and improved plasma HDL-cholesterol:total cholesterol ratio compared with chickens receiving the control diet. Chickens given the $\mathrm{CH} 2000$ chitosan diet had significantly elevated plasma HDL:total cholesterol ratio compared with both control and CH9-fed animals on day 21 . However, by day 19 , feeding the CH510 chitosan diet significantly 
Table 4. Plasma triacylglycerol, total cholesterol, HDL-cholesterol and HDL-cholesterol: total cholesterol (HDL: total) of broiler chickens given control or chitosan-containing diets*

\begin{tabular}{|c|c|c|c|c|c|c|}
\hline & \multirow[b]{2}{*}{ Control diet } & \multicolumn{3}{|c|}{ Chitosan-containing diets } & \multirow[b]{2}{*}{ Pooled SEM ${ }^{\dagger}$} & \multirow{2}{*}{$\begin{array}{c}\text { Statistical } \\
\text { significance of } \\
\text { differencet: } P=\end{array}$} \\
\hline & & $\mathrm{CH} 9$ & $\mathrm{CH} 510$ & $\mathrm{CH} 2000$ & & \\
\hline \multicolumn{7}{|l|}{ Day 12} \\
\hline Triacylglycerols (mM) & $0 \cdot 37^{\mathrm{a}}$ & $0 \cdot 29^{b}$ & $0.37^{\mathrm{a}}$ & $0.36^{\mathrm{a}}$ & 0.02 & 0.31 \\
\hline \multicolumn{7}{|l|}{ Plasma cholesterol (mM) } \\
\hline Total & $6 \cdot 49^{\mathrm{a}}$ & $5.73^{\mathrm{ab}}$ & $5 \cdot 55^{\mathrm{ab}}$ & $5 \cdot 42^{\mathrm{b}}$ & $0-33$ & 0.02 \\
\hline HDL & $2 \cdot 94^{a}$ & $2 \cdot 69^{\mathrm{a}}$ & $3 \cdot 04^{a}$ & $3 \cdot 11^{\mathrm{a}}$ & $0 \cdot 15$ & 0.95 \\
\hline HDL: total & $0.46^{a}$ & $0.48^{a}$ & $0.55^{\mathrm{ab}}$ & $0.58^{\mathrm{b}}$ & 0.03 & 0.05 \\
\hline \multicolumn{7}{|l|}{ Day 19} \\
\hline Triacylglycerols (mM) & $0-34^{\mathrm{a}}$ & $0.31^{\mathrm{a}}$ & $0.32^{\mathrm{a}}$ & $0.34^{\mathrm{a}}$ & 0.01 & 0.68 \\
\hline \multicolumn{7}{|l|}{ Plasma cholesterol (mM) } \\
\hline Total & $7 \cdot 50^{\mathrm{a}}$ & $6 \cdot 19^{\mathrm{b}}$ & $6 \cdot 45^{\mathrm{ab}}$ & $6.73^{\mathrm{ab}}$ & 0.38 & 0.03 \\
\hline HDL & $3 \cdot 07^{\mathrm{a}}$ & $2 \cdot 95^{a}$ & $3 \cdot 25^{\mathrm{a}}$ & $2 \cdot 94^{\mathrm{a}}$ & 0.14 & 0.91 \\
\hline HDL: total & $0.41^{\mathrm{a}}$ & $0.48^{\mathrm{ab}}$ & $0.51^{\mathrm{b}}$ & $0 \cdot 45^{\mathrm{ab}}$ & 0.03 & 0.05 \\
\hline
\end{tabular}

a,b Means within a row not sharing a common superscript letter were significantly different $(P<0 \cdot 05)$.

* For details of diets and procedures, see Tables 1 and 2 and pp. 388-390.

$\dagger$ df 12.

$\ddagger$ Control v. chitosan-containing diets.

increased plasma HDL-cholesterol:total cholesterol ratio when compared with birds receiving the control diet only.

\section{Digestibility study}

Diet influenced the ileal digesta DM content $(P=0.04)$ as well as the ileal digestibility of crude protein $(P=0.04)$, crude fat $(P=0.02)$, glucose and uronic acid residues $(P=0.02)$. Feeding chitosan-containing diets significantly reduced digesta DM content $(P<0.05)$ and generally reduced ileal crude protein, crude fat and organic matter digestibility in comparison with control feeding (Table 5). Feeding the $\mathrm{CH} 9$ chitosan diet significantly reduced $(P<0.05)$ the ileal digestibility of crude fat and organic matter compared with the control diet, while the $\mathrm{CH} 2000$ chitosan diet significantly reduced crude protein, crude fat and organic matter ileal digestibilities. The reduction in ileal crude fat digestibility among chickens given the $\mathrm{CH} 9, \mathrm{CH} 510$ and $\mathrm{CH} 2000$ chitosan diets was $7 \cdot 0,5.8$ and $9 \cdot 3 \%$ respectively.

An increase in the ileal digestibility of dietary-fibre polysaccharides in chickens given chitosan-containing diets in relation to animals given the control diets was also observed. The increased ileal digestibilities of glucose and uronic acids with chitosan feeding were significant when compared with the respective ileal digestibilities among control-fed animals.

Chickens given the control diet generally had increased, although not significantly, caecal acetic, propionic and butyric acid concentrations in comparison with chickens given the $\mathrm{CH} 9$ and $\mathrm{CH} 2000$ chitosan diets (Table 6). Feeding the $\mathrm{CH} 9$ chitosan diet did significantly reduce $(P<0.05)$ the caecal propionic acid concentration compared with that of controlfed chicks, while feeding the CH510 chitosan diet tended to increase the caecal concentrations of these components compared with chickens given the control diet. Acetic acid was the predominant SCFA, accounting for $68 \%$ of the total SCFA. 
Table 5. Digesta DM content $(\mathrm{g} / \mathrm{kg})$ and apparent ileal digestibilities of nutrients and dietaryfibre polysaccharide residues in last one-third of small intestine of broiler chickens given control or chitosan-containing diets*

\begin{tabular}{|c|c|c|c|c|c|c|}
\hline & \multirow[b]{2}{*}{ Control diet } & \multicolumn{3}{|c|}{ Chitosan-containing diets } & \multirow[b]{2}{*}{ Pooled SEM $\dagger$} & \multirow{2}{*}{$\begin{array}{c}\text { Statistical } \\
\text { significance of } \\
\text { differencef: } P=\end{array}$} \\
\hline & & $\mathrm{CH} 9$ & $\mathrm{CH} 510$ & $\mathrm{CH} 2000$ & & \\
\hline Digesta DM content & $250^{\mathrm{a}}$ & $235^{b}$ & $230^{\mathrm{b}}$ & $236^{\mathrm{b}}$ & $5 \cdot 7$ & 0.01 \\
\hline \multicolumn{7}{|l|}{ Ileal digestibility } \\
\hline Crude protein $(\mathrm{N} \times 6.25)$ & $0 \cdot 73^{\mathrm{a}}$ & $0.72^{\mathrm{a}}$ & $0.71^{a b}$ & $0.70^{\mathrm{b}}$ & $0-006$ & 0.03 \\
\hline Crude fat & $0.86^{a}$ & $0 \cdot 80^{\mathrm{b}}$ & $0 \cdot 81^{\text {ab }}$ & $0 \cdot 78^{\mathbf{b}}$ & 0.015 & 0.01 \\
\hline Starch & $0.94^{a b}$ & $0.93^{a}$ & $0-96^{\mathrm{b}}$ & $0.94^{\mathrm{ab}}$ & 0.007 & 0.60 \\
\hline Organic matter & $0 \cdot 80^{\mathrm{a}}$ & $0 \cdot 78^{b}$ & $0 \cdot 79^{\mathrm{ab}}$ & $0.78^{\mathbf{b}}$ & $0 \cdot 007$ & 0.03 \\
\hline \multicolumn{7}{|c|}{ Dietary-fibre polysaccharide residues } \\
\hline Arabinose & $-0.54^{\mathrm{a}}$ & $-0.48^{\mathrm{ab}}$ & $-0 \cdot 46^{\mathrm{ab}}$ & $-0 \cdot 38^{\mathbf{b}}$ & $0 \cdot 047$ & 0.08 \\
\hline Xylose & $-0.57^{\mathrm{a}}$ & $-0.45^{a b}$ & $-0.44^{\mathrm{ab}}$ & $-0.37^{b}$ & $0 \cdot 051$ & 0.07 \\
\hline Glucose & $-0 \cdot 30^{\mathrm{a}}$ & $-0 \cdot 18^{\mathrm{b}}$ & $-0 \cdot 10^{\mathrm{b}}$ & $-0.09^{\mathbf{b}}$ & $0 \cdot 045$ & 0.01 \\
\hline Uronic acids & $-0 \cdot 10^{a}$ & $-0 \cdot 17^{a}$ & $0.13^{b}$ & $0 \cdot 22^{b}$ & $0 \cdot 084$ & $0 \cdot 14$ \\
\hline $\begin{array}{l}\text { Total dietary-fibre } \\
\text { polysaccharide residues }\end{array}$ & $-0 \cdot 34^{a}$ & $-0 \cdot 30^{\mathrm{ab}}$ & $-0 \cdot 24^{a b}$ & $-0 \cdot 19^{b}$ & 0.041 & 0.01 \\
\hline
\end{tabular}

a, $b$ Means within a row not sharing a common superscript letter were significantly different $(P<0 \cdot 05)$.

* For details of diets and procedures, see Tables 1 and 2 and pp. 388-390

$\dagger$ df 12 .

$\ddagger$ Control $v$. chitosan-containing diets.

Table 6. Caecal short-chain fatty acid (SCFA) content $(\mathrm{mg} / \mathrm{g} D M)$ from caeca of broiler chickens given control or chitosan-containing diets*

\begin{tabular}{|c|c|c|c|c|c|c|}
\hline & \multirow[b]{2}{*}{ Control diet } & \multicolumn{3}{|c|}{ Chitosan-containing diets } & \multirow[b]{2}{*}{ Pooled SEM $\dagger$} & \multirow{2}{*}{$\begin{array}{c}\text { Statistical } \\
\text { significance } \\
\text { of difference }+: P=\end{array}$} \\
\hline & & $\mathrm{CH} 9$ & CH510 & $\mathrm{CH} 2000$ & & \\
\hline Acetic acid & $33 \cdot 9^{a}$ & $24 \cdot 5^{\mathrm{a}}$ & $36 \cdot 4^{\mathrm{a}}$ & $30 \cdot 5^{\mathrm{a}}$ & $4 \cdot 4$ & 0.52 \\
\hline Acetic acid:total SCFA & $0.69^{a}$ & $0.70^{\mathrm{a}}$ & $0 \cdot 67^{a}$ & $0.66^{\mathrm{a}}$ & 0.02 & 0.79 \\
\hline Propionic acid & $8 \cdot 30^{\mathrm{a}}$ & $5 \cdot 50^{\mathrm{b}}$ & $9 \cdot 50^{a}$ & $8 \cdot 03^{\mathrm{ab}}$ & $1 \cdot 0$ & 0.57 \\
\hline Propionic acid: total SCFA & $0 \cdot 16^{\mathrm{a}}$ & $0 \cdot 16^{\mathrm{a}}$ & $0 \cdot 18^{a}$ & $0 \cdot 19^{a}$ & 0.02 & 0.67 \\
\hline Butyric acid & $7 \cdot 61^{\mathrm{a}}$ & $5 \cdot 23^{a}$ & $7.65^{a}$ & $7 \cdot 00^{\mathrm{a}}$ & $1 \cdot 3$ & 0.54 \\
\hline Butyric acid: total SCFA & $0 \cdot 15^{\mathrm{a}}$ & $0 \cdot 15^{\mathrm{a}}$ & $0 \cdot 14^{\mathrm{a}}$ & $0 \cdot 15^{\mathrm{a}}$ & $0 \cdot 13$ & 0.81 \\
\hline Total SCFA & $49 \cdot 8^{a}$ & $35 \cdot 2^{\mathrm{a}}$ & $53 \cdot 6^{\mathrm{a}}$ & $45 \cdot 5^{a}$ & 5.9 & 0.49 \\
\hline
\end{tabular}

a,b Means within a row not sharing a common superscript letter were significantly different $(P<0.05)$.

* For details of diets and procedures, see Tables 1 and 2 and pp. 388-390.

$\dagger$ df 12.

$\ddagger$ Control $v$. chitosan diets.

\section{Duodenal and ileal digesta $\mathrm{pH}$}

Duodenal and ileal digesta $\mathrm{pH}$ were not significantly affected by diet (Table 7). Mean duodenal $\mathrm{pH}$ was found to be 5.80 , and 7.57 for ileal samples. However, chitosan feeding tended to elevate, although not significantly, duodenal and ileal $\mathrm{pH}$.

\section{Ileal digesta viscosity}

Ileal digesta viscosity was not significantly influenced by diet (Table 7). The greatest ileal digesta viscosity was observed among chickens given the CH510 chitosan diet, although 
Table 7. Duodenal and ileal digesta $p H$ and ileal digesta viscosity (mPa.s) of broiler chickens given control or chitosan-containing diets*

\begin{tabular}{|c|c|c|c|c|c|c|}
\hline & \multirow[b]{2}{*}{ Control diet } & \multicolumn{3}{|c|}{ Chitosan-containing diets } & \multirow[b]{2}{*}{ Pooled SEM $\dagger$} & \multirow{2}{*}{$\begin{array}{c}\text { Statistical } \\
\text { significance } \\
\text { of difference } \neq: P=\end{array}$} \\
\hline & & СH9 & CH510 & CH2000 & & \\
\hline Duodenal digesta $\mathrm{pH}$ & 5.68 & 5.92 & 5.77 & $5 \cdot 78$ & $0 \cdot 15$ & 0.65 \\
\hline Ileal digesta $\mathrm{pH}$ & $7 \cdot 31$ & 7.49 & 7.81 & 7.65 & $0 \cdot 26$ & 0.59 \\
\hline Ileal digesta viscosity (mPa.s) & $1 \cdot 14$ & $1 \cdot 15$ & $1 \cdot 36$ & 0.98 & 0.84 & 0.81 \\
\hline
\end{tabular}

* For details of diets and procedures, see Tables 1 and 2 and pp. 388-390.

+ df 12.

$\ddagger$ Control $v$. chitosan diets; all differences were not significant.

this value was not significantly greater than the ileal digesta viscosity of animals fed on the other diets.

\section{DISCUSSION}

It is now generally accepted that soluble dietary fibres increase gastrointestinal lumen viscosity (Edwards, 1990) and delay gastric emptying (Chang, 1983). However, it has proved difficult to measure intestinal viscosity reliably in vivo as physiological shear rates are not known. In the present experiment the low intestinal viscosity observed among chickens given the chitosan-containing diets could have resulted from precipitation of the polymer in the ileum, the low chitosan inclusion level or difficulty in the actual measurement of viscosity.

Chitosans solubilize to form highly viscous solutions at low pH (Furda, 1983) and precipitate at a $\mathrm{pH}$ greater than 6.0 . This is of interest since chitosan solubility and, hence, increased intestinal viscosity would be confined to the upper gastrointestinal tract, while polymeric precipitation in the terminal ileum would reduce intestinal viscosity since polysaccharides do not confer viscosity when insoluble (Morris, 1990). Nevertheless, the increased water-binding capacity of the chitosans was observed in the present experiment in the reduced ileal digesta DM contents of chitosan-fed animals compared with controlfed chickens, suggesting increased ileal lumen viscosity. However, no significant evidence of increased ileal viscosity as a result of feeding chitosan-containing diets in comparison with control-fed animals was observed. This would tend to support the suggestion that chitosans precipitating in the more neutral $\mathrm{pH}$ of the small intestine (Furda, 1983) would, therefore, no longer confer increased viscosity to the ileal digesta.

Feeding chitosan-containing diets did not significantly reduce body weights and feed intakes when compared with those of the control-fed animals. Feeding diets containing $30 \mathrm{~g}$ chitosan $/ \mathrm{kg}$ to broiler chickens has been shown to reduce feed intakes and body weights significantly in comparison with feeding a control (low-fibre) diet (Razdan \& Pettersson, 1994). This suggests that the level of chitosan inclusion in the present experiment was too low for differences between control and chitosan-containing diets, as well as differences between chitosan-containing diets, to be apparent in the production study. Some watersoluble dietary fibres are known to influence lipid metabolism profoundly (Anderson $e t$ al. 1990), and chitosans have been shown recently to alter bile acid composition, increase neutral sterol excretion and reduce ileal fat digestibility (Fukada et al. 1991 ; Maezaki et al. 1993; Razdan \& Pettersson, 1994). The mechanisms by which chitosans achieve these effects are not fully established, although increased intestinal viscosity and increased bile acid-binding capacity are two proposals currently favoured (Furda, 1990). 
Chitosans solubilize in the acidic conditions of the stomach and in so doing probably increase intrinsic gastric viscosity. It has been proposed that increased gastrointestinal viscosity increases the thickness of the intestinal unstirred water layer and in so doing reduces nutrient uptake (Flourie et al. 1984). In the present study, chitosan feeding generally tended to reduce total plasma cholesterol concentrations compared with those of animals given the control diet, but these reductions could not be related to increased intestinal viscosity at the site of lipid absorption in the ileum. However, viscosity as a factor in controlling plasma lipid concentrations and lipid uptake cannot be dismissed entirely from the present experiment, since the shear rate used in viscometric analysis was low and probably bears no relation to the physiological shear rate. It is plausible, however, that factors other than increased intestinal viscosity may be responsible for the observed effects.

Chitosans have been shown to bind bile acids in vitro at low $\mathrm{pH}$ (Nauss et al. 1983). The low $\mathrm{pH}$ of the glandular stomach of chickens would enable solubilization of chitosans to form a highly-charged solution in the upper gastrointestinal tract. As the solubilized chitosans pass through the duodenum into the jejunum, the elevated $\mathrm{pH}$ results in precipitation of the polyglucosamines and bile acid-binding capacity is reduced. It has been suggested that chitosan precipitation and the consequent diminished bile acid-binding potential in the lower gastrointestinal tract enables bile acid reabsorption (Furda, 1983), although a recent human study has revealed that bile acids are indeed excreted after chitosan ingestion (Maezaki et al. 1993), as are dietary fatty acids in rats (Deuchi et al. 1994). A further contribution to these bile acid losses may result from renewed binding of bile acids in the acidic caecum. Losses of bile acids would affect enterohepatic bile acid metabolism by draining the bile acid pool. Bile acids bound or sequestered in the duodenum pass through the gastrointestinal tract and are excreted in the form of primary (Maezaki et al. 1993) and secondary bile acids resulting in increasing hepatic synthesis of compensatory primary bile acids from endogenous cholesterol (Anderson \& Tietyen-Clark, 1986).

Increases in HDL-cholesterol concentrations are often associated with feeding of chitosans, since increased requirements for cholesterol by the liver for synthesis of bile acids lost by excretion or conversion of primary to secondary bile acids stimulates transport of cholesterol from peripheral tissues to the liver in a process known as reverse cholesterol transport. In the present experiment, however, although plasma HDL-cholesterol:total cholesterol ratios of birds given chitosan-containing diets were generally increased relative to those of control-fed birds, this could largely be attributed to decreases in total plasma cholesterol rather than increases in plasma HDL-cholesterol concentrations.

Ileal digestibilities of crude protein and crude fat were reduced as a result of chitosan feeding relative to control feeding in the present experiment. This is noteworthy since chitosan-containing diets contained a greater proportion of fat than the control diet. The greater fat content in the chitosan-containing diet would be expected perhaps to increase ileal fat digestibility and elevate plasma lipid concentrations. In the present experiment, however, total plasma cholesterol concentrations were generally reduced among chickens given chitosan-containing diets in comparison with those given the control diet.

Although the greatest reductions in crude protein and fat digestibilities were observed for chickens given the $\mathrm{CH} 2000$, high-viscosity-chitosan-containing diet, differences between chitosan-containing diets were small and no definite correlation between chitosan-fraction viscosity and reduced nutrient absorption could be established. Mixing and dilution of feed in the gizzard would contribute to the lack of differences in viscosity between the diets.

As mentioned earlier, a substantial contribution to reduced ileal crude fat digestibility as a result of chitosan-feeding may have come from binding of the chitosan complex to mixed lipid micelles. However, feeding the three chitosan-containing diets tended to reduce ileal 
fat digestibility to a similar extent when compared with control-fed animals, which is surprising when the large differences in chitosan fraction viscosity and crude fat content in these diets are taken into account. The low chitosan inclusion level was probably responsible for the similar reductions of ileal crude fat digestibility among chickens given the chitosan-containing diets compared with control-fed animals. The ileal digestibility of dietary-fibre polysaccharide residues generally increased with feeding diets with increasing chitosan-fraction viscosity in comparison with the control diet in the present experiment. The apparent uronic acid ileal digestibility among chickens given the $\mathrm{CH} 510$ and $\mathrm{CH} 2000$ chitosan-containing diets was significantly greater than that for birds given the control diet. Uronic acids present in the diets of the present study are anions and, therefore, may be bound or sequestered by chitosans. Since soluble chitosans probably precipitated in the jejunum of chitosan-fed chickens in the present study, intestinal transit time would be reduced as insoluble fibres tend to increase gastrointestinal passage rate (Anderson, 1985). This would result in a more rapid passage of sequestered uronic acids through the jejunum and ileum and account for the apparent increase in ileal uronic acid digestibility.

Feeding the $\mathrm{CH} 9$ chitosan diet reduced caecal acetic, propionic and butyric acids as well as total SCFA concentrations (derived from bacterial fermentation) compared with the control diet. With the exception of the reduction in propionic acid concentration, however, none of the observed reductions was significant relative to those for chickens given the control diet. Chitosans have been demonstrated to reduce proliferation of bacteria in vivo (Tanigawa et al. 1992; Darmadji \& Izumimoto, 1994) as well as caecal SCFA concentrations in broiler chickens (Razdan \& Pettersson, 1994). The binding of polycationic chitosans to polyanions in bacterial cell membranes, resulting in precipitation of these complexes under favourable conditions (Katchalski et al. 1964), may be responsible for the bacteriocidic effects of chitosans. Tanigawa et al. (1992) suggested that the inhibitory effect of a 1.3-5 g chitosan/1 solution on bacteria was dependent on the degree of deacetylation of the polyglucosamines, based on the observation that a greater degree of deacetylation decreased bacterial number to the greatest extent in vitro. In the present in vivo study, however, no such relationship was observed since the $\mathrm{CH} 510$ chitosan diet with the greatest degree of deacetylation ( $89 \%$ ) actually resulted in increased total SCFA concentrations.

The hypolipidaemic properties of the polyglucosamine chitosan was demonstrated in the present experiment in the reduced plasma cholesterol concentrations and increased HDLcholesterol:total cholesterol ratio of chickens fed on chitosan-containing diets. The influence of chitosan on the ileal digestibility of, in particular, dietary crude fat was also indicated. The similarity in ileal digesta viscosities between control and chitosan-fed animals suggested that mechanisms other than increased ileal viscosity may also have been responsible for reduced plasma cholesterol concentrations and reduced ileal digestibility of dietary lipids. Although chitosan may have bacteriocidic properties in vitro, little evidence to support this was observed in our in vivo chicken study.

The usefulness of broiler chickens as a model animal for the study of gastrointestinal responses to dietary fibre and, in particular, the effect of dietary fibre on lipid uptake is observed from the results of the present experiment. Since the young broiler chicken is sensitive to feeding of fibre, effects are often enhanced and reliable results can be obtained even if the fibre inclusion level is low.

The authors are indebted to Pronova Biopolymers of Drammen, Norway for providing them with the chitosan fractions. The assistance of Börje Eriksson with GLC samples at Kungsängen, Swedish University of Agricultural Sciences, Uppsala is gratefully acknowledged. This work was financially supported by the Swedish Council for Forestry and Agricultural Research. 


\section{REFERENCES}

Åman, P. \& Hesselman, K. (1984). Analysis of starch and other constituents of cereal grains. Swedish Journal of Agricultural Research 14, 135-139.

Anderson, J. W. (1985). Physiological and metabolic effects of dietary fiber. Federation Proceedings 44, 2902-2932.

Anderson, J. W., Deakins, D. A., Floore, T. L., Smith, B. M. \& Whitis, S. E. (1990). Dietary fiber and coronary heart disease. Critical Reviews in Food Science and Nutrition 29, 95-147.

Anderson, J. W. \& Tietyen-Clark, J. (1986). Dietary fiber: hyperlipidemia, hypertension and coronary heart disease. American Journal of Gastroenterology 81, 907-919.

Anon (1971). Determination of crude oil and fats. Official Journal of the European Communities L297, 995-997.

Association of Official Analytical Chemists (1984). Official Methods of Analysis, 14th ed. Washington, DC: Association of Official Analytical Chemists.

Chang, M. L. W. (1983). Dietary pectin: effect on metabolic processes in rats. In Unconventional Sources of Dietary Fiber. American Chemical Society Symposium Series no. 214, pp. 143-154 [I. Furda, editor]. Washington, DC: American Chemical Society.

Darmadji, P. \& Izumimoto, M. (1994). Effect of chitosan in meat preservation. Meat Science 38, 243-254.

Deuchi, K., Kanauchi, O., Imasato, Y. \& Kobayashi, E. (1994). Decreasing effect of chitosan on the apparent fat digestibility by rats fed on a high-fat diet. Bioscience, Biotechnology and Biochemistry 58, 1613-1616.

Edwards, C. (1990). Mechanisms of action on dietary fibre on small intestinal absorption and motility. In New Developments in Dietary Fiber, pp. 95-104 [I. Furda and C. J. Brine, editors]. New York: Plenum Press.

Fenton, T. W. \& Fenton, M. (1979). An improved procedure for the determination of chromic acid in feed and feces. Canadian Journal of Animal Science 59, 631-634.

Flourie, B., Vidon, N., Florent, C. H. \& Bernier, J. J. (1984). Effect of pectin on jejunal glucose and unstirred layer thickness in normal man. Gut 25, 936-941.

Fukada, Y., Kimura, K. \& Ayaki, Y. (1991). Effect of chitosan feeding on intestinal bile acid metabolism in rats. Lipids 26, 395-399.

Furda, I. (editor) (1983). Aminopolysaccharides - their potential as dietary fiber. In Unconventional Sources of Dietary Fiber. American Chemical Society Symposium Series no. 214, pp. 105-122. Washington, DC: American Chemical Society.

Furda, I. (1990). Interaction of dietary fiber with lipids - mechanistic theories and their limitations. In New Developments in Dietary Fiber, pp. 67-82 [I. Furda and C. J. Brine, editors]. New York: Plenum Press.

Ikeda, I., Sugano, M., Yoshida, K., Sasaki, E., Iwamoto, Y. \& Hatano, K. (1993). Effects of chitosan hydrolysates on lipid absorption and on serum and liver lipid concentrations in rats. Journal of Agricultural and Food Chemistry 41, 431-435.

Johnson, I. T. \& Gee, J. M. (1981). Effect of gel-forming gums on the intestinal unstirred layer and sugar transport in vitro. Gut 22, 398-403.

Katchalski, E., Sela, M., Silman, H. I. \& Berger, A. (1964). Polyamino acids as protein models. In The Proteins, pp. 405-602 [H. Neurath, editor]. New York: Academic Press.

Knorr, D. (1991). Recovery and utilisation of chitin and chitosan in food processing waste management. Food Technology 45, 114-122.

Maezaki, Y., Tsuji, K., Nakagawa, Y., Kawai, \& Akimoto, M. (1993). Hypocholesterolemic effect of chitosan in adult males. Bioscience, Biotechnology and Biochemistry 57, 1439-1444.

Morris, E. R. (1990). Physical properties of dietary fibre in relation to biological function. In Dietary Fibre: Chemical and Biological Aspects, pp. 91-102 [D. A. T. Southgate, K. Waldron, I. T. Johnson and G. R. Fenwick, editors]. Cambridge: Royal Society of Chemistry.

Nauss, J.L., Thompson, J.L. \& Nagyvary, J. (1983). The binding of micellar lipids to chitosan. Lipids 18, $714-719$

Pettersson, D. \& Åman, P. (1992). Production responses and serum lipid concentrations of broiler chickens fed diets based on oat bran and extracted oat bran with and without enzyme supplementation. Journal of the Science of Food and Agriculture 58, 569-576.

Razdan, A. \& Pettersson, D. (1994). Effect of chitin and chitosan on nutrient digestibility and plasma lipid concentrations in broiler chickens. British Journal of Nutrition 72, 277-288.

Statistical Analysis Systems Institute Inc. (1985). SAS User's Guide: Statistics. Cary, NC: SAS Institute Inc.

Sugano, M., Fujikawa, T., Hiratsuji, Y., Nakashima, K., Fukuda, N. \& Hasegawa, Y. (1980). A novel use of chitosan as a hypocholesterolemic agent in rats. American Journal of Clinical Nutrition 33, 787-793.

Sugano, M., Watanabe, S., Kishi, A., Izume, M. \& Ohtakara, A. (1988). Hypocholesterolemic action of chitosans with different viscosity in rats. Lipids $\mathbf{2 3}, 187-191$.

Tanigawa, T., Tanaka, Y., Sashiwa, H., Saimoto, H. \& Shigemasa, Y. (1992). Various biological effects of chitin derivatives. In Advances in Chitin and Chitosan, pp. 206-215 [C. J. Brine, P. A. Sandford and J. P. Zikakis, editors]. London: Elsevier Science Publishers.

Theander, O. \& Westerlund, E. (1986). Studies on dietary fibers. 3. Improved procedures for analysis of dietary fibers. Journal of Agricultural and Food Chemistry 34, 330-336. 